\title{
The dream is still alive...
}

We are highly pleased to publish issue \# 1 of the $20^{\text {th }}$ volume of the Journal of the Brazilian Chemical Society, JBCS.

We are celebrating twenty continuous years of a scientific journal published in English in Brazil. That 1987 dream, when the planning for the journal started, came to be a challenge in 1990, with the releasing of the first JBCS issue. The scenario and expectations of that time are reflected in two parts of the first JBCS editorial, written by Professor Eduardo Motta Alves Peixoto, ${ }^{1}$ its founder and first Editor:

"In Brazil, as in many other countries, it has been immensely difficult to establish a balance between national development and the investment in chemistry. It is still commonly thought that economic growth necessarily and justifiably entails the sacrifice of basic research. A change of mentality is required, with the more active and purposeful participation of industries, government and the scientific community, so that by the year 2000 scientific research may be managed realistically and effectively..."

"...Our mission and our commitment are to the present and future generations, safeguarding the prosperity and welfare of the world with the best in the chemical research. Not just a new international journal."

During these 20 years, chemistry in Brazil has undergone many transformations: from an essentially academic activity to a sector that produces knowledge and that especially issues patents for the industrial sector, continually improving the academic area excellence.

In the same period, the Brazilian chemistry community has witnessed a number of governmental investment plans in which the chemical sector had an outstanding participation. For example, the Scientific and Technological Development Support Program PADCT, in the 80's and 90's, supported JBCS creation and represented a differential growth for the chemical sector. Other programs were created and modified in the last two decades, such as the Support Program to Outstanding Teams - PRONEX, the Sectorial Funds and the Millenium Institutes.

But Professor Peixoto's dream of seeing a joint participation of industries, government and scientific community came true on November 27,2008, with the announcement by the Science and Technology Ministry and the National Council for Technological and Scientific Development - MCT / CNPq of the establishment of 101 National Science and Technology Institutes - INCTs (http://www.cnpq.br/saladeimprensa/noticias/2008/1127.htm). The INCTs will receive investments of about R \$ 600 millions (US\$ 300 millions) coming from the Science and Technology Ministry, the Health Ministry, the Industry and Commerce Development Ministry, Governmental Agencies (CNPq, the Brazilian Federal Agency for Support and Evaluation of Graduate Education - CAPES, the Research and Projects Financing FINEP), the Research Supporting Foundations from the states of Amazon, Para, Sao Paulo, Minas Gerais, Rio de Janeiro and Santa Catarina (FAPEAM, FAPESPA, FAPESP, FAPEMIG, FAPERJ and FAPESC), the Brazilian Development Bank - BNDES and the Brazilian Oil Company - Petrobras. It is the greatest joint initiative for investing in science, technology and innovation involving a large and decentralized network, with offices in all regions of Brazil. The future has arrived! "... so that by the year 2000 scientific research may be managed realistically and effectively..." and the dream is still alive...
Ten years ago, $\boldsymbol{J B C} \boldsymbol{S}$ celebrated its first inclusion in the Journal of Citation Reports, JCR, with an expressive impact factor (IF) of 0.293. In less than ten years, the IF barrier of 1.0 was surpassed and here we are, in the year 20, with an IF of 1.539, which positions $\boldsymbol{J B C S}$ as the main scientific journal in Latin America and the Caribbean. In the last three years, the number of submitted papers for publication was over 700 a year and the percentage of papers from abroad was over $50 \%$, which proves its international character. ${ }^{2}$ But, “...Not just a new international journal", for, among the 27 countries from which we receive manuscripts, Iran, China and India ${ }^{2}$ outstand for having a differentiated position in the world scenario concerning diplomatic, scientific and/or economic matters. Publishing the results of high quality research, independently of the fact that those research results were produced in Brazil or abroad is associated with the prosperity and well being of humanity. Our mission and commitment to the Brazilian society are preserved.

During these 20 years, $\boldsymbol{J B C S}$ has gone through several changes in order to maintain its financial support, periodicity, visibility and the increase of the number of published articles, with no quality loss. It is worth noting that, for more than 10 years, its articles have been accessible on the internet free of charge. And the future? As we all know, predicting is a difficult and risky task. However, the present way of making research results public and the peer evaluation, which permitted the scientific development of the XXth century and the beginning of this century, are on focus, being the target of publications and editorials in several regions of the planet. The use of scientific journal citations and the citations of scientists as a means of evaluation, widespread in the last ten years, have been "under evaluation". There is no new model yet, but there is a feeling that the flaws in the present model equal or surpass its virtues...

The spread of the display on electronic means and the constant improvement of the searching systems are making the electronic access to any kind of publication in any language or format possible. This will affect the present scientific periodicals and those able to foresee the courses of the changes will survive. JBCS will certainly do.

Publishing a periodical like $\boldsymbol{J B C S}$ for twenty continuous years has been the task of many, whom we deeply thank: the Brazilian Chemical Society, which, since the very beginning, associated its growth and establishment with a high quality editorial line; the funding agencies, especially CNPq, CAPES, FAPESP e FINEP, which supported the journal even during difficult times; all those who dedicate themselves to the hard work of management, herein represented by Dr. Elizabeth Magalhaes and Ms. Dirce Campos; former and present members of our editor and referee board, who share their professional and familiar time with $\boldsymbol{J B C S}$ with no privilege or financial reward at all and, most of all, the authors who honor the journal with their excellent scientific works. Bound for the future, because the dream is still alive...

Jailson B. de Andrade (UFBA) Editor JBCS

\section{References}

1. Peixoto, E.M.A.; J. Braz. Chem. Soc. 1990, $1,1$.

2. Pinto, A. C.; Cunha, A. S.; Quim. Nova 2008, 31, 2221. 